\title{
Risk factors for outbreaks of infectious pancreatic necrosis (IPN) and associated mortality in Norwegian salmonid farming
}

\author{
Britt Bang Jensen*, Anja B. Kristoffersen
}

Norwegian Veterinary Institute, Section for Epidemiology, 0106 Oslo, Norway

\begin{abstract}
Infectious pancreatic necrosis (IPN) has for many years been considered one of the most important restraints to the production of salmonids in European aquaculture. In Norway, the disease is responsible for high losses in post-smolts in the first few weeks after sea transfer. Despite the importance of IPN, there are few epidemiological studies on risk factors and mitigation strategies. In this paper, we present analyses of data from all cohorts put to sea in 2009 to 2012 on Norwegian marine salmonid farms. The data used were obtained from national registers on salmonid production and disease outbreaks. The results showed that the risk of IPN outbreak was higher for spring versus autumn cohorts, Atlantic salmon versus rainbow trout and for cohorts on farms with previous history of IPN. The risk increased with increasing cohort size and infection pressure, whereas increasing temperature and weight at sea transfer decreased the risk. Estimations from a model of cumulative mortality within the first 6 mo after sea transfer showed that mortality in cohorts with IPN increased to approximately 7.2\% as compared to a 'baseline' cohort with a mortality of $3.4 \%$. If the cohort had both IPN and pancreas disease (PD), the estimated mortality increased to $12.9 \%$, and cohorts with both IPN, PD and heart and skeletal muscle inflammation (HSMI) had an estimated mortality of $16.6 \%$, when all other significant factors were kept constant (these were cohort type, year, temperature at sea transfer and weight at sea transfer). Our results provide valuable inputs for mitigation strategies and for economic modelling of consequences of disease.
\end{abstract}

KEY WORDS: Infectious pancreatic necrosis virus - IPNV · Salmo salar - Oncorhynchus mykiss · Pancreas disease $\cdot$ PD $\cdot$ Heart and skeletal muscle inflammation $\cdot$ HSMI $\cdot$ Epidemiology $\cdot$ Mortality

\section{INTRODUCTION}

Infectious pancreatic necrosis (IPN) has for many years been considered one of the most important restraints to the production of salmonids in European aquaculture, due to the high number of annual outbreaks and the associated high mortality in affected aquaculture farms (Ariel \& Olesen 2002). During the last decade, 119 to 223 farms in Norway have experienced a clinical outbreak annually. Most of these outbreaks were in marine farms (Hjeltnes 2014). IPN is caused by an aquabirnavirus, IPNV, and both vertical and horizontal transmission modes have been described (Bovo et al. 2005, OIE 2006). IPN was originally described as a disease affecting salmonid fry and fingerlings in freshwater hatcheries in North America and subsequently northern Europe. However, since the 1980s, it has been reported in marine farms with increasing prevalence and distribution. In addition, surveys and case reports have documented the occurrence of IPNV or other birnaviruses in numerous aquatic animal species around the world. 
IPN occurs in both freshwater and marine water salmonid farming, and all age groups can be infected. IPN-associated mortality varies from negligible up to $90 \%$, and is often higher during outbreaks in the freshwater phase (Munro \& Midtlyng 2011). However, the economic consequences of outbreaks in the marine grow-out phase are likely higher, since each individual fish has a higher monetary value. Susceptibility to infection and the ensuing mortality is dependent on species, age or developmental stage, virus strain and fish strain, but environmental and management factors also seem to be influential (Munro \& Midtlyng 2011). In addition to the direct disease-associated mortality, it has been suggested that fish surviving IPN outbreaks are more susceptible to other diseases, i.e. heart and skeletal muscle inflammation (HSMI) or pancreas disease (PD) (Smail et al. 1992).

Previous studies of risk factors for clinical outbreaks of IPN have shown that smolts put to sea in the spring (S1 smolts) have a much higher risk of getting clinical IPN than smolts put to sea in the fall (S0 smolts). Also, the use of many smolt suppliers and stocking with $>400000$ smolts increased the risk of clinical outbreaks. Geographic location of a farm also affected the risk of IPN (Jarp et al. 1995, Raynard et al. 2005, Murray 2006).

Most Norwegian salmonid smolts are vaccinated against IPNV before sea transfer, but the vaccine does not seem to offer full protection against infection, even though it is believed to reduce outbreakassociated losses (Brun 2003). In recent years, the focus for reducing IPN-associated losses has been on the eradication of certain 'house strains' in hatcheries and breeding towards disease resistance (Hjeltnes 2014). In the last few years, there has been a reduction in the number of outbreaks in Norway, which has been attributed to the aforementioned mitigation measures.

However, the industry still reports significant losses in individual outbreaks due to mortalities and subsequent weakening of surviving fish. Knowledge of the impact of specific individual mitigation measures is paramount when advising farmers which measures to take towards reducing losses. Thus, the relative influence of different management and environmental factors on the production losses associated with IPN needs to be clarified.

The aim of the present study was therefore to investigate risk factors influencing both the probability of IPN outbreak and the degree of mortality during the first 6 mo of the seawater phase of salmonid farming in Norway.

\section{MATERIALS AND METHODS}

\section{Study population}

We studied Atlantic salmon (Salmo salar) and rainbow trout (Oncorhynchus mykiss) smolt cohorts put to sea in 2009 to 2012. Data on different production parameters were obtained from a database hosted by the Norwegian Food Safety Authority (NFSA), to which farmers must report every month (for further description of these data, see Kristoffersen et al. 2009). A cohort was defined as all smolts put to sea at one farm within the same time period. Only cohorts that were being actively farmed at the same location for the first $6 \mathrm{mo}$ in the sea were included. To ensure that cohorts that had been transferred from other farms were not included, only cohorts of fish with an average weight less than $250 \mathrm{~g}$ at sea transfer were included. There were no overlapping cohorts at any farm.

\section{IPN case definition}

A list of recorded IPN cases from 2007 to 2013 on identified farms, including the month when samples were received at the Norwegian Veterinary Institute (NVI), was compiled from the laboratory information system at the NVI. The list included all cases in which IPN was diagnosed either by histopathology or PCR, or both. Reporting of IPN is not compulsory, but reporting of elevated mortalities is mandatory and the causes must be investigated. Hence, the list probably includes most of the clinical IPN cases. Furthermore, all Norwegian aquaculture production farms are required by legislation to undergo clinical inspections by fish health officers 6 to 12 times a year, depending on type of production (NFD 2008). Therefore, any case of IPN that has not been reported by the farmer will probably be discovered at these inspections. All cohorts with no report of IPN during the study period were defined as control cohorts. Due to the time interval of the study period, more than 1 cohort from a given farm was sometimes included. These cohorts never overlapped in time, but a farm could harbor both a case and a control cohort following each other. Fig. 1 shows a map of the farms included in the study, with an indication of the numbers of cohorts with an IPN case on each farm. 


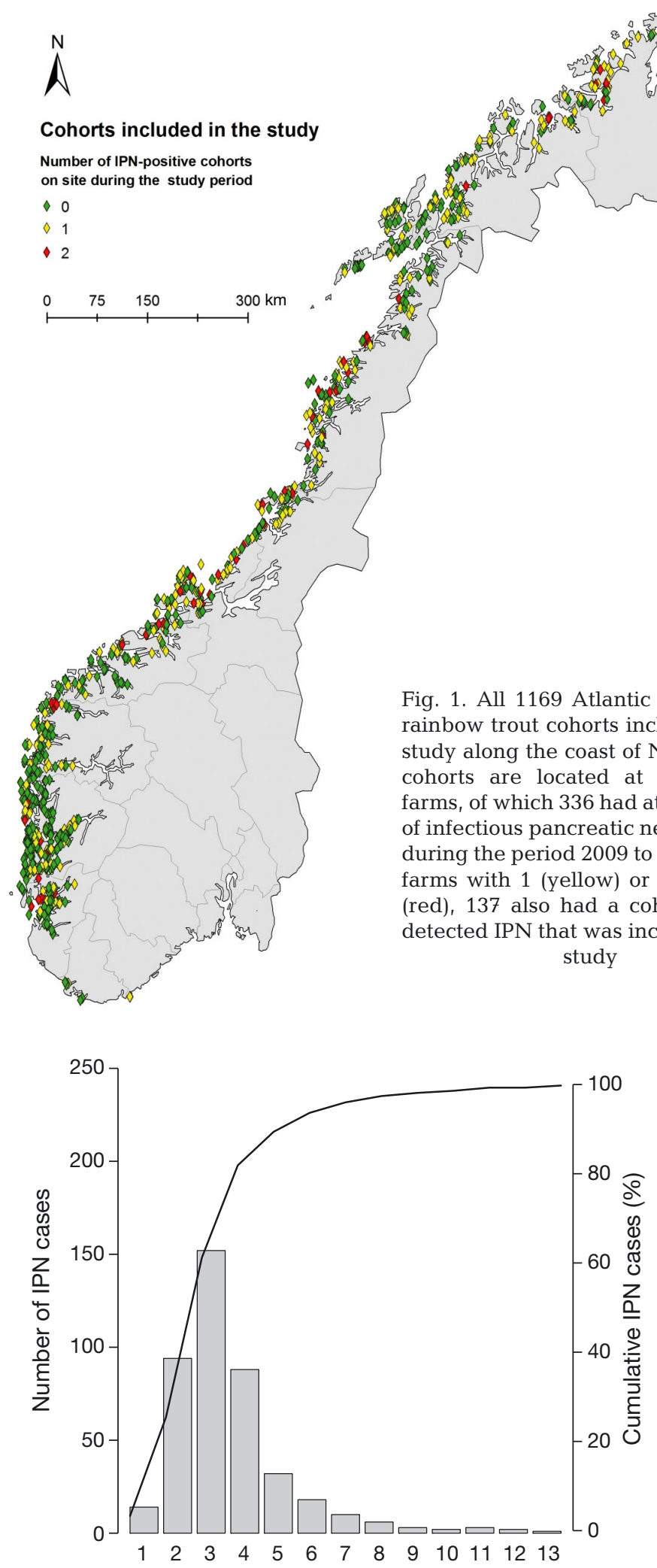

Number of months before IPN detection after sea transfer

Fig. 2. Number of IPN cases detected against number of months after sea transfer. The solid line shows the cumulative percentage of IPN cases detected within $x$ months

\section{Calculation of mortality}

Mortality data per cohort on a monthly basis were obtained from the NFSA database. Based on the time of sea transfer and the time of diagnosis of IPN, the number of months in the sea from sea transfer to IPN outbreak was calculated. As seen in Fig. 2, 93.6\% of the IPN cases occur within the first 6 mo after transfer to sea. This is consistent with findings by Kilburn et al. (2012) and Brun (2003). We therefore chose to use cumulative percent mortality within the first 6 mo at sea as the outcome variable for all cohorts, both with and without IPN diagnosis. A total of 27 cohorts that were diagnosed with IPN after Month 6 were removed from the dataset.

\section{Independent variables}

Data on weight at sea transfer, species, number of fish in cohort, total cage volume on farm and temperature on a monthly basis were all extracted from the NFSA database. From January 2012 to August 2013, the sea temperature data were obtained on a weekly basis. These were transformed to monthly data by calculating the mean over the weeks included in 1 mo. From the obtained data, we calculated the following variables:

(1) Cohort type: Cohorts were split into spring smolt (S1) cohorts, those cohorts put to sea between March and July, and autumn smolt (S0) cohorts, which were put to sea between August and February.

(2) Temperature difference: For every fish cohort transferred to sea, the temperature difference was calculated as the temperature in the 6th month in the sea minus the temperature in the 1st month in the sea.

(3) Cohort size: For each cohort, the maximum number of fish at any one time during the first 6 mo in the sea was extracted.

(4) Maximum density: The maximum density was calculated as maximum number of fish per volume $\left(1 \mathrm{~m}^{-3}\right)$ at any one time during the first $6 \mathrm{mo}$ in the sea.

(5) IPN in previous cohorts: For each cohort, it was checked whether IPN had occurred in previous cohorts on the same farm within the last $2 \mathrm{yr}$.

(6) Other diseases: Lists of reported cases of HSMI and PD were retrieved from the laboratory informa- 
tion system at the NVI. HSMI is diagnosed through histopathology, whereas PD is diagnosed either by PCR or by histopathology. Both diseases are notifiable on a national level, and thus the lists should be exhaustive. A cohort was included as a PD case if it had a PD diagnosis within the first 6 mo after sea transfer, and similarly for HSMI.

(7) Infection pressure: Infection pressure was defined as exposure to infection by proximate infectious farms. Different scenarios for infection pressure were tested (see Bang Jensen et al. 2013) with the following formula:

$$
i p_{i}(t)=S_{i}(t) \cdot \sum_{j \in N_{i}(t)} \frac{I_{j}(t) x_{j}(t)}{d_{i j}}
$$

where $i$ is the cohort for which the infection pressure $\left(i p_{i}\right)$ was calculated in month $t, S_{i}$ is 1 if the fish in cohort $i$ were susceptible $(S)$ and 0 otherwise, $N_{i}(t)$ is all active cohorts within a proximity of $i$ in month $t$, $I_{j}(t)$ is 1 if cohort $j$ was infectious in month $t$ and 0 if not, $d_{i j}$ is the seaway distance between cohort $i$ and cohort $j_{1}$ and $x_{j}(t)$ is 1 or the biomass or the size of cohort $j$ in month $t$.

(8) Geo-index: For each farm, a geo-index was calculated as the position of the farm along a local polynomial regression line, which was based on the longitude and the latitude of each farm included in the study. All farms were sorted based on their latitude, with the first farm in the far south given the geoindex 0 , and increasing along the coast ending with the most northerly farm having the geo-index 29.9. For more details on the calculation, see Kristoffersen et al. (2013).

(9) Use of IPN-resistant smolts: For a subset of the population, we were able to obtain data on whether or not the cohort had included IPN-resistant smolts in the form of smolts bred specifically with a selection towards resistance for IPN, based on an identified quantitative trait locus (QTL) (Houston et al. 2008, Moen et al. 2009). These data were obtained from a provider of QTL-IPN eggs, who had followed the eggs from hatchery to cohort in the sea. Thus, we had information on the use of QTL-smolts in a total of 487 cohorts, owned by several different companies. The proportion of QTL-positive fish included in these cohorts was not available, so a cohort was defined as QTL+ if it had received smolts from at least 1 hatchery producing QTL+ smolts, and QTL- if it had not received smolts from any such hatcheries. Thus, 13 of 264 cohorts were defined as QTL+ in 2010, 25 of 178 in 2011 and 4 of 45 in 2012, accordingly.

(10) IPN in the freshwater phase: For a subset of the population, additional data on which hatcheries had delivered smolts to each farm were obtained through a questionnaire. The questionnaire covered 187 cohorts that were put to sea in 2010 to 2012 and owned by 3 large companies. The cohorts included all cohorts owned by the 3 large companies, and thus included both IPN-negative and IPN-positive cohorts, with approximately the same distribution of IPN as the entire dataset. We used the list of IPN cases described above to ascertain which hatcheries had reported clinical IPN outbreaks. Often, the cohort included smolts received from several different hatcheries. If a cohort had received smolts from at least 1 hatchery with clinical IPN, it was included in the category 'IPN hatchery: positive'. If a cohort had not received smolts from any hatcheries with clinical IPN, it was included in the category 'IPN hatchery: negative'.

\section{Statistical modelling approach}

Multivariate logistic regression was used to explore differences between case and control cohorts. The mortality $(m)$ for all cohorts was modeled using linear regression. Mortality was tested both as linear and log-linear; the latter was preferred based on modeling of diagnostic plots of the residuals. For both models, pre-analysis was done using generalized additive models (GAMs) and splines allowing the relationships between the independent and the dependent variables to be non-linear (Hastie \& Tibshirani 1996). Variables that were found to have a non-linear relation were transformed such that all variables ended up having a linear relation. Akaike's information criterion (AIC) comparison between the regression with a spline function and the transformed variables was used to ensure that the transformation explained as much as the spline did. AIC was also used to compare the different infection pressure scenarios in a univariate logistic regression model for each scenario using GAM and spline function. The scenario with the lowest AIC value in the logistic model was used further, both in the multivariable logistic analysis and the multivariable log-linear mortality analysis. All possible correlations between variables were tested, and variables with correlations higher than 0.7 were not used in the same model. A total of 398 case and 771 control cohorts were included. To compare the contribution from each variable in the final logistic regression model, an analysis based on standardized variables (mean set to 0 , SD to 1) was conducted, and the odds ratio (OR) for each variable was calculated. 


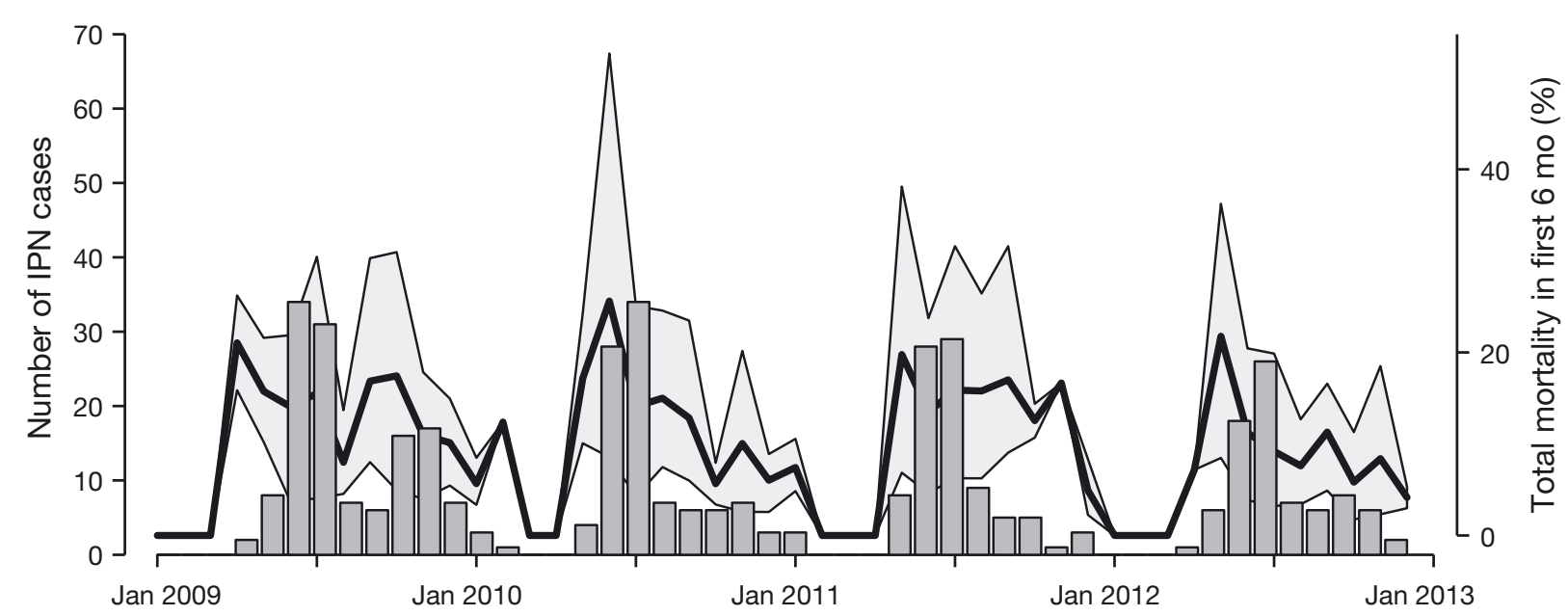

Fig. 3. Number of IPN cases detected each month (bars), with the mean (solid line), and 10th-90th percentile observed mortality (corresponding shaded area) during the first 6 mo in the sea

The final model based on the entire study population was used to calculate a predicted value $(\hat{y})$ for the subsets of the population for which we had data on the use of IPN-resistant smolts, number of hatcheries delivering smolts, or IPN in the freshwater phase (as described in the previous sections). The $\hat{y}$ from the final model was then included in a semi-univariate logistic regression model estimating the probability of an IPN diagnosis for each cohort, using the following formula:

$$
\operatorname{logit}\left(p_{i}\right)=a+\hat{y}_{i}+b x_{i j}
$$

where $p_{i}$ is the probability of IPN in cohort $i, \hat{y}$ is the predicted value for $\operatorname{logit}\left(p_{i}\right)$ calculated from the final logistic regression model of cohort $i$, and $j$ is IPN in the freshwater phase, number of smolt suppliers, or IPN-resistant smolts in cohort. In order to identify any possible biases in these subsets of data, we tested for confounders between the explanatory variables and the outcome variables.

In the same manner as for the logistic regression model, the final log-linear mortality model was used to calculate a predicted mortality $\left(\hat{m}_{i}\right)$ for each cohort $i$ with extra information. This predicted mortality was used as an offset in a semi-univariate log-linear mortality regression:

$$
\log \left(m_{i}\right)=a+\log \left(\hat{m}_{i}\right)+b x_{i j}
$$

All programming was done in the statistical programming environment $\mathrm{R}$ 3.0.2 (R Core Team 2013). Data from January 2009 to June 2013 were included in the regression analysis, while infection pressure was calculated based on data from 2007 to July 2013.

\section{RESULTS}

\section{Descriptive statistics}

The number of monthly IPN detections in the period January 2009 to December 2012 varied from 0 to 34. Most of the detections were in the summer months. The total mortality during the first 6 mo after sea transfer in the IPN cohorts varied substantially (min: $3.9 \%$, max: $28.4 \%$, mean: $14 \%$ ). There was a tendency for the mortality to peak in the summer months, together with the number of detections (Fig. 3). The length of the stocking period was $17.6 \mathrm{mo}$ (80\% interval 11 to 23$)$, which was equal for spring and autumn smolts.

Descriptive statistics of all independent variables and their relationship with the total percentage mortality in the first 6 mo in the sea are presented in Table 1. Comparing AIC values from the univariate analysis of the dataset showed that IPN detection was the best predictor of cumulative mortality during the first $6 \mathrm{mo}$ in the sea, followed by cohort type, temperature at sea transfer and temperature difference between Months 1 and 6 (Table 1). All the variables tested were significant $(p<0.05)$.

\section{Model fitting}

In this study, we found that the model for infection pressure that best described IPN detection in a logistic model was one where cohorts were assumed to be infectious 2 mo before IPN detection (or sea transfer at the earliest) until 2 mo after IPN 
Table 1. Descriptive statistics for the potential variables and their relationship with the outcome variable: total mortality in Atlantic salmon and rainbow trout in the first 6 mo after sea transfer. A total of 1169 cohorts were included in the study. The result of the univariate log mortality linear regression is summarized by Akaike's information criterion (AIC; the null model had an AIC of 3284). All the tested variables were significant $(p<0.05)$. IPN: infectious pancreatic necrosis; HSMI: heart and skeletal muscle inflammation; PD: pancreas disease. See 'Materials and methods' for details on the variables

\begin{tabular}{|c|c|c|c|c|c|c|c|}
\hline \multirow{2}{*}{ Variable } & \multirow[t]{2}{*}{ Levels } & \multirow{2}{*}{$\overline{\text { Mean (SD) }}$} & \multicolumn{2}{|c|}{ - Distribution } & \multicolumn{2}{|c|}{ Total mortality (\%) } & \multirow[t]{2}{*}{$\mathrm{AIC}$} \\
\hline & & & $80 \%$ range & Quartiles & Mean & $80 \%$ range & \\
\hline \multirow[t]{2}{*}{ IPN first 6 mo } & No & 771 & & & 6 & $1.2-12.8$ & 3001 \\
\hline & Yes & 398 & & & 14 & $3.9-28.4$ & \\
\hline \multirow[t]{2}{*}{ Cohort type } & Spring & 649 & & & 10.9 & $2.3-23.2$ & 3154 \\
\hline & Autumn & 520 & & & 5.9 & $1.1-12.9$ & \\
\hline \multirow{4}{*}{$\begin{array}{l}\text { Temperature } \\
\text { at sea transfer } \\
\left({ }^{\circ} \mathrm{C}\right)\end{array}$} & & $9.3(3.5)$ & 5.0 to 14.3 & $<6.7$ & 11.8 & $2.5-24.9$ & 3163 \\
\hline & & & & $6.7-8.9$ & 9.7 & $2.1-19.4$ & \\
\hline & & & & $8.9-12.0$ & 7.9 & $1.1-18.8$ & \\
\hline & & & & $>12.0$ & 5.4 & $1.3-11.6$ & \\
\hline \multirow{4}{*}{\multicolumn{2}{|c|}{$\begin{array}{l}\text { Temperature } \\
\text { in Month } 6 \text { minus } \\
\text { temperature in Month } 1 \\
\left({ }^{\circ} \mathrm{C}\right)\end{array}$}} & $-0.8(6.5)$ & -9.3 to 7.6 & $<-6.9$ & 5.5 & $1.2-11.6$ & 3165 \\
\hline & & & & $-6.9-0.0$ & 7.5 & $1.1-17.3$ & \\
\hline & & & & $0.0-5.0$ & 9.5 & $2.2-19.3$ & \\
\hline & & & & $>5.0$ & 12.1 & $2.5-26.7$ & \\
\hline \multirow[t]{4}{*}{ Year } & 2009 & 287 & & & 10.1 & $1.9-19-3$ & 3225 \\
\hline & 2010 & 295 & & & 10.4 & $2.1-24.8$ & \\
\hline & 2011 & 297 & & & 8.1 & $1.5-17.4$ & \\
\hline & 2012 & 290 & & & 6.2 & $1.1-13.9$ & \\
\hline \multirow[t]{2}{*}{ HSMI first 6 mo } & No & 1043 & & & 8.3 & $1.4-18.1$ & 3258 \\
\hline & Yes & 126 & & & 11.6 & $2.8-24.8$ & \\
\hline \multirow{4}{*}{\multicolumn{2}{|c|}{$\begin{array}{l}\text { Infection pressure } \\
\left(1 \mathrm{~km}^{-1}\right)\end{array}$}} & $0.11(0.08)$ & 0.008 to 0.22 & $<0.04$ & 8 & $1.0-17.9$ & 3261 \\
\hline & & & & $0.04-0.10$ & 8.3 & $1.4-19.6$ & \\
\hline & & & & $0.10-0.22$ & 8.6 & $1.7-17.5$ & \\
\hline & & & & $>0.22$ & 10 & $2.0-22.2$ & \\
\hline \multirow{4}{*}{\multicolumn{2}{|c|}{$\begin{array}{l}\text { Max. density } \\
\text { (ind. } \mathrm{m}^{-3} \text { ) }\end{array}$}} & $9.2(4.6)$ & 4.2 to 14.9 & $<5.3$ & 6.6 & $1.0-14.7$ & 3262 \\
\hline & & & & $5.3-8.4$ & 8.1 & $1.7-16.8$ & \\
\hline & & & & $8.4-11.7$ & 10 & $2.0-22.7$ & \\
\hline & & & & $>11.7$ & 9.9 & $1.7-22.2$ & \\
\hline \multirow{4}{*}{\multicolumn{2}{|c|}{$\begin{array}{l}\text { Cohort size } \\
\left(10^{3}\right)\end{array}$}} & $882(516)$ & 303 to 1576 & $<507$ & 7.4 & $1.1-16.2$ & 3265 \\
\hline & & & & $507-806$ & 8.6 & $1.7-19.0$ & \\
\hline & & & & 806-1144 & 9.1 & $1.7-18.0$ & \\
\hline & & & & $>1144$ & 9.7 & $1.7-22.8$ & \\
\hline \multirow[t]{2}{*}{ PD first $6 \mathrm{mo}$} & No & 1095 & & & 8.5 & $1.5-18.8$ & 3274 \\
\hline & Yes & 74 & & & 11.6 & $2.4-23.2$ & \\
\hline \multirow{4}{*}{\multicolumn{2}{|c|}{$\begin{array}{l}\text { Weight at } \\
\text { sea transfer }(g)\end{array}$}} & $114(38)$ & 73 to 165 & $<87$ & 9.9 & $1.7-22.8$ & 3281 \\
\hline & & & & $87-107$ & 8.6 & $1.6-19.4$ & \\
\hline & & & & $107-133$ & 8.2 & $1.5-16.6$ & \\
\hline & & & & $>133$ & 8.1 & $1.5-17.0$ & \\
\hline \multirow[t]{2}{*}{ Species } & Salmon & 1086 & & & 8.9 & $1.5-19.6$ & 3282 \\
\hline & Rainbow trout & 83 & & & 6.3 & $1.7-13.2$ & \\
\hline \multirow{4}{*}{$\begin{array}{l}\text { Geo-index } \\
\text { (see text) }\end{array}$} & & $10.6(7.9)$ & 2.7 to 21.3 & $<3.5$ & 7.4 & $1.3-17.2$ & 3282 \\
\hline & & & & $3.5-8.67$ & 8.7 & $1.6-18.2$ & \\
\hline & & & & $8.67-16.7$ & 10.1 & $1.6-23.4$ & \\
\hline & & & & $>16.7$ & 8.6 & $1.7-17.3$ & \\
\hline \multirow[t]{2}{*}{ IPN last 2 yr } & No & 948 & & & 8.4 & $1.4-18.2$ & 3282 \\
\hline & Yes & 221 & & & 9.9 & $1.7-21.6$ & \\
\hline
\end{tabular}

detection, hence $I_{j}(t)=1$ in this timespan, and 0 if otherwise, and all neighbors within $100 \mathrm{~km}$ were assumed to contribute, independent of biomass or size, hence $x_{j}(t)=1$.
When the infection pressure exceeded 0.22 , the probability of getting IPN did not increase further, hence in the model we used a cut-off for infection pressure of 0.22 . 
Table 2. Parameter estimates and p-values from the multivariate logistic modeling of the probability of infectious pancreatic necrosis (IPN) detection. The odds ratio (OR) for each estimate is provided. The continuous variables were scaled to mean 0 and SD 1, so that the OR corresponds to an increase of 1 unit change in the scaled variables. $\triangle \mathrm{AIC}$ is the increase in Akaike's information criterion (AIC) for the full model without that variable. The variables have been ranked according to the importance of their contribution to the model (based on

$\triangle \mathrm{AIC}$ ). SCE: standardized coefficient estimate; CI: confidence interval

\begin{tabular}{|lccccc|}
\hline Variable & SCE & SE & p & OR (95\% CI) & $\Delta$ AIC \\
\hline Intercept & -0.24 & 0.14 & 0.081 & & \\
Cohort size & 0.49 & 0.07 & $<0.001$ & $1.62(1.41-1.87)$ & 46 \\
Cohort type = spring & 0.5 & 0.1 & $<0.001$ & $1.65(1.37-1.99)$ & 26 \\
Year (2009) & 0 & & & & 24 \\
Year (2010) & -0.74 & 0.2 & $<0.001$ & & \\
Year (2011) & -0.96 & 0.2 & $<0.001$ & & \\
Year (2012) & -0.94 & 0.21 & $<0.001$ & & \\
Species = salmon & 0.46 & 0.14 & $<0.001$ & $1.59(1.21-2.08)$ & 16 \\
Temperature at sea transfer & -0.38 & 0.1 & $<0.001$ & $0.68(0.56-0.83)$ & 13 \\
Infection pressure & 0.27 & 0.07 & $<0.001$ & $1.31(1.13-1.51)$ & 11 \\
IPN last 2 yr & 0.22 & 0.07 & 0.001 & $1.25(1.09-1.43)$ & 8 \\
Weight at sea transfer & -0.2 & 0.07 & 0.007 & $0.81(0.71-0.95)$ & 6 \\
ayear is a factor and is not standardized, hence no OR is calculated for this \\
variable
\end{tabular}

decreased by 0.68. Similarly, mean smolt weight above $114 \mathrm{~g}$ at sea transfer reduced the odds of getting IPN.

The model was used for predicting the risk of developing IPN as a function of cohort size given 3 different scenarios: (1) a cohort with spring smolts, situated on a farm that had experienced IPN within the previous $2 \mathrm{yr},(2)$ a cohort with spring smolts on a farm with no previous history of IPN, and (3) a cohort with autumn smolts on a farm that had experienced IPN within the previous 2 yr. In all 3 scenarios, species were set as salmon, year as 2012, and the medians for temperature at sea transfer and weight at sea transfer were used. The $80 \%$ range of infection pressure was calculated for all scenarios. In all 3 scenarios, the predicted probability of IPN increased by almost $20 \%$

Temperature at sea transfer and temperature difference between Months 1 and 6 turned out to be highly correlated variables (correlation $=-0.88$ ), and could not be used in the same model. Models were compared with either one of them, and AIC values for both IPN detection and mortality indicated that temperature at sea transfer was the best explanatory variable.

The final logistic regression model describing the probability of IPN detection for each cohort can be found in Table 2. The final model describing loglinear cumulative mortality can be found in Table 3 .

No confounding effects from any explanatory variables were found in the semi-univariate analyses including only the subsets of data.

\section{Risk factors for IPN}

The risk factors that were significant for increasing the probability of IPN detection were (in order of significance based on $\triangle \mathrm{AIC}$ ): increasing cohort size, cohort type (spring vs. autumn smolts), year, species (salmon vs. trout), decreasing temperature at sea transfer, increasing infection pressure, IPN on farm within the last $2 \mathrm{yr}$ and decreasing mean weight at sea transfer (Table 2). For every increase in cohort size of 1 SD (516000 fish), the odds of getting IPN increased by 1.62 . For a temperature increase at sea transfer of $3.5^{\circ} \mathrm{C}$ above $9.3^{\circ} \mathrm{C}$, the odds of getting IPN when the cohort size increased from 400000 to 1.6 million (Fig. 4). The mean predicted probability was $\sim 10 \%$ higher for spring smolt cohorts on farms with previous IPN (Scenario 1) than for spring smolt cohorts without (Scenario 2). Spring cohorts on farms without previous IPN (Scenario 2) had a $5 \%$ higher probability of IPN that autumn cohorts (Scenario 3), but the difference was negligible if the infection pressure of autumn smolt cohorts was high (Fig. 4).

Table 3. Parameter estimates and p-values from the multivariate modeling of $\log$ (percent mortality during first 6 mo after sea transfer). $\triangle \mathrm{AIC}$ is the increase in Akaike's information criterion (AIC) for the full model without that variable. The deviance explained by the model was 32.8. Variables are ranked according to the importance of their contribution to the model (based on $\triangle \mathrm{AIC})$. SCE: standardized coefficient estimate; IPN: infectious pancreatic necrosis; PD: pancreas disease; HSMI: heart and skeletal muscle inflammation

\begin{tabular}{|lrrrr|}
\hline Variable & SCE & SE & p & $\Delta$ AIC \\
\hline Intercept & -2.77 & 0.05 & $<0.001$ & \\
IPN first 6 mo & 0.35 & 0.03 & $<0.001$ & 171 \\
Year (2009) & 0 & & & 55 \\
Year (2010) & 0.06 & 0.07 & 0.388 & \\
Year (2011) & -0.18 & 0.07 & 0.008 & \\
Year (2012) & -0.43 & 0.07 & $<0.001$ & \\
PD first 6 mo & 0.14 & 0.02 & $<0.001$ & 33 \\
Temperature at sea transfer & -0.14 & 0.03 & $<0.001$ & 17 \\
Cohort type = spring & 0.12 & 0.03 & $<0.001$ & 14 \\
HSMI first 6 mo & 0.08 & 0.02 & 0.002 & 8 \\
Weight at sea transfer & -0.07 & 0.02 & $<0.001$ & 5 \\
\hline
\end{tabular}




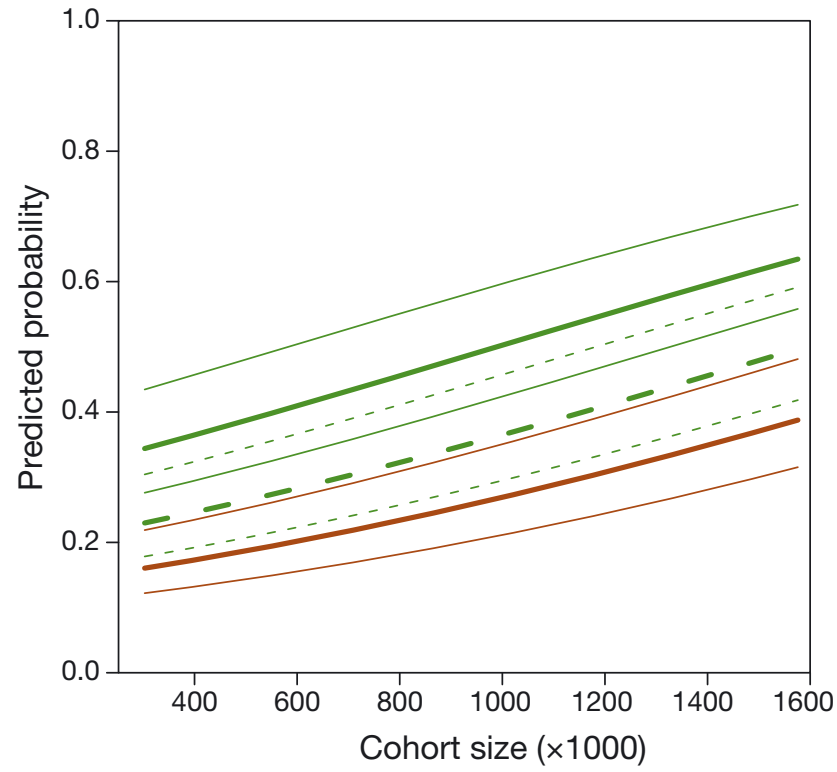

Fig. 4. Predicted probability of IPN outbreak with increasing cohort size, as calculated by the model described in Table 2 . Three scenarios are shown: (1) a cohort with spring smolts (S1), situated on a farm that had experienced IPN within the previous 2 yr (solid green line), (2) a cohort with spring smolts (S1) on a farm with no previous history of IPN (dashed green line) and (3) a cohort with autumn smolts (S0) on a farm that had experienced IPN within the previous $2 \mathrm{yr}$ (solid brown line). The median infection pressure is indicated by the thick lines, and the $80 \%$ variance interval by the thin lines

\section{Risk factors for mortality}

The risk factors that were significant for increasing the log percent mortality during the first 6 mo in the sea were (in order of significance, based on $\triangle \mathrm{AIC}$ ): IPN in the first 6 mo, year of sea transfer, PD in the first $6 \mathrm{mo}$, temperature at sea transfer, cohort type, HSMI in the first 6 mo and weight at sea transfer (Table 3). The higher the temperature at sea transfer and the higher the mean weight at sea transfer, the lower the predicted mortality for a cohort, following the same pattern as for IPN outbreak. The mortality decreased over the years studied here, with the lowest mortality occurring in the last year of the study. There was no significant difference in mortality between the first 2 years (2009 and 2010), but the difference between these years and 2011 was statistically significant, as was the difference between 2009 and 2012 (Table 3). Spring cohorts in general had a higher mortality (mean: $10.9 \%$ ) than autumn cohorts (mean: $5.9 \%$ ).

In Fig. 5, we demonstrate how the mean mortality in the first 6 mo varied with different scenarios: a 'baseline scenario' for cohorts without IPN, 'IPN' for

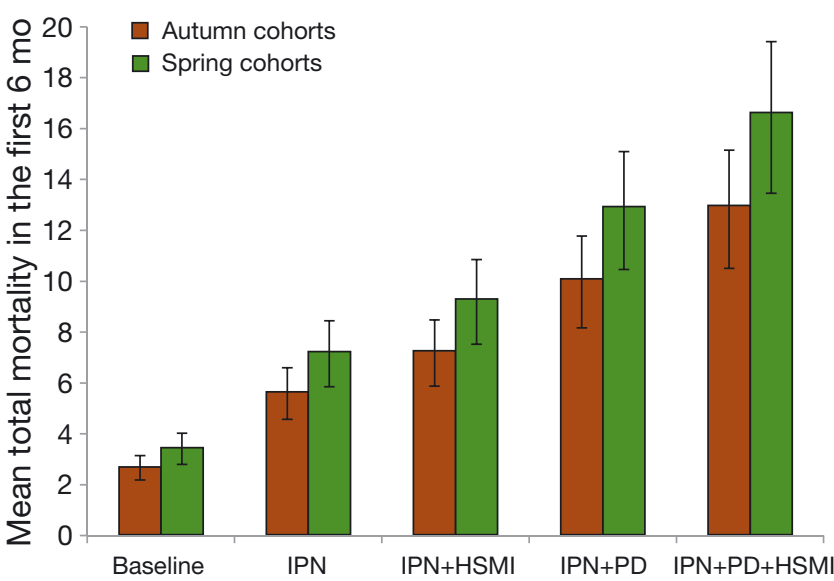

Fig. 5. Mean total mortality during the first $6 \mathrm{mo}$ in the sea for spring and autumn cohorts, given different scenarios: Baseline (no infectious pancreatic necrosis [IPN], heart and skeletal muscle inflammation [HSMI] or pancreas disease [PD]), only IPN, IPN and HSMI, IPN and PD, and IPN, PD and HSMI. For all scenarios, weight at sea transfer $=$ median $(107 \mathrm{~g})$ and temperature at sea transfer $=$ median $\left(9.92^{\circ} \mathrm{C}\right)$. Lower bar: $10 \%$ level of temperature at sea transfer, upper bar: $90 \%$ level of temperature at sea transfer

cohorts with only IPN, 'IPN+PD' or 'IPN+HSMI' for cohorts with 2 of the diseases included in the model, and 'IPN+PD+HSMI' for cohorts with all 3 diseases. For this figure, weight at sea transfer was kept constant at the median (107 g), the year was 2012, and the variation due to temperature at sea transfer is shown. The mean mortality increased from $3.4 \%$ in the baseline scenario for spring cohorts to $7.2 \%$ in spring cohorts with IPN, and additionally to $12.9 \%$ and $16.6 \%$ for spring cohorts that also had PD and PD+HSMI, respectively (Fig. 5).

Additional information from a subset of cohorts. Finally, the calculated predicted $\hat{y}$ values from the 2 different models were used for each cohort as an offset for calculating the probability of IPN and predicted mortality in semi-univariate analysis (Table 4). Only IPN in hatcheries turned out to be a significant explanatory variable for the mortality model: Cohorts that came from hatcheries where IPN had been detected had higher mortality in the sea than cohorts that did not come from hatcheries with detected IPN. This was independent of whether IPN had also been detected in these cohorts in the sea phase or not.

\section{DISCUSSION}

Our study identifies important risk factors for the development of IPN in Norwegian marine salmonid production, and the effect of different risk factors on 
Table 4. Statistical results for a subset of Atlantic salmon and rainbow trout cohorts for which data on use of quantitative trait locus (QTL) fish, presence of infectious pancreatic necrosis (IPN) in hatchery and number of smolt suppliers were available. Descriptive statistics, univariate regression and semi-univariate regression based on those cohorts with information on each of the 3 additional variables are given here for each of the models' logistic regression of IPN detection, along with the log-linear total mortality during the first 6 mo for all cohorts. p-values are given for each regression, and slope $(b)$ is given for significant regressions

\begin{tabular}{|c|c|c|c|c|c|c|c|c|c|c|c|}
\hline \multirow[t]{3}{*}{ Variable } & \multirow[t]{3}{*}{ Levels } & \multirow[t]{3}{*}{ Distrib. } & \multirow{3}{*}{$\begin{array}{l}\text { No. of IPN } \\
\text { detections }\end{array}$} & \multicolumn{2}{|c|}{ Test p-values } & \multicolumn{2}{|c|}{ Total mortality (\%) } & \multicolumn{4}{|c|}{ Regression statistics } \\
\hline & & & & \multirow[t]{2}{*}{$\chi^{2}$ test } & \multirow[t]{2}{*}{ Semi-univ } & \multirow[t]{2}{*}{ Mean } & \multirow[t]{2}{*}{$80 \%$ range } & \multicolumn{2}{|c|}{ Univ. } & \multicolumn{2}{|c|}{ Semi-univ. } \\
\hline & & & & & & & & $\mathrm{p}$ & $b$ & $\mathrm{p}$ & $b$ \\
\hline \multirow{2}{*}{$\begin{array}{l}\text { QTL } \\
\text { status }\end{array}$} & $+\mathrm{ve}$ & 42 & 13 & \multirow[t]{2}{*}{0.374} & \multirow[t]{2}{*}{0.192} & 9.5 & $1.2-25.2$ & \multirow[t]{2}{*}{0.581} & & \multirow[t]{2}{*}{0.925} & \\
\hline & $-\mathrm{ve}$ & 443 & 168 & & & 9.6 & $1.8-22.4$ & & & & \\
\hline \multirow{6}{*}{$\begin{array}{l}\text { IPN in } \\
\text { hatchery } \\
\text { No. of smolt } \\
\text { suppliers }^{\mathrm{a}}\end{array}$} & Yes & 102 & 57 & \multirow[t]{2}{*}{0.290} & \multirow[t]{2}{*}{0.457} & 10.4 & $2.7-20.8$ & \multirow[t]{2}{*}{$<0.001$} & \multirow[t]{2}{*}{0.23} & \multirow[t]{2}{*}{0.040} & \multirow[t]{2}{*}{0.10} \\
\hline & No & 85 & 54 & & & 7.1 & $1.4-17.5$ & & & & \\
\hline & 1 & 74 & 31 & \multirow[t]{4}{*}{0.743} & \multirow[t]{4}{*}{0.772} & 7.4 & $1.8-15.5$ & \multirow[t]{4}{*}{0.207} & & \multirow[t]{4}{*}{0.435} & \\
\hline & 2 & 83 & 32 & & & 8.9 & $2.5-18.0$ & & & & \\
\hline & 3 & 26 & 12 & & & 9.8 & $1.4-23.2$ & & & & \\
\hline & 4 & 4 & 1 & & & 28.3 & $8.8-53.3$ & & & & \\
\hline
\end{tabular}

mortality within the first 6 mo of the sea phase of the production cycle. The risk factors are divided into inherent factors (e.g. species and smolt type), internal environmental factors (e.g. size of cohort and co-infections with other diseases), and external environmental factors (e.g. infection pressure, temperature and geographical location). For outbreaks of IPN, it appears that the most important factors are those that are inherent or those that can be controlled on the farm.

The size of the cohort was the most important risk factor for outbreaks of IPN (based on $\triangle$ AIC). The odds of getting IPN increased by 1.62 for every addition of approximately 500000 smolts. The same effect has been found for other diseases in Norwegian salmon farming (i.e. HSMI: Kristoffersen et al. 2013; cardiomyopathy syndrome: Bang Jensen et al. 2013). We found that spring smolts had a higher probability of IPN and that they experienced a higher mortality in general than autumn smolts. This is consistent with reports from Scotland and with previous studies in Norway (Jarp et al. 1995, Raynard et al. 2005), which demonstrated that spring smolts had a higher probability of getting IPN. The temperature at sea transfer was generally lower for this group than for autumn smolts, and since low temperature at sea transfer is a risk factor, this could be an explanation for the higher occurrence of IPN for spring smolts. However, when tested, we found no correlation between temperature at sea transfer and spring smolts. Raynard et al. (2005) concluded that the effect of temperature on IPN outbreaks was mostly due to a coincidental association with spring smolts. We think it is more likely that the higher risk of IPN for spring smolts results from the fact that most outbreaks happen in the summer months, within the first 3 mo after sea transfer for this type of smolt. From our data, we saw that $>60 \%$ of the outbreaks occurred within the first 3 mo after transfer to the sea, and this was equal for both spring and autumn smolts. For other viral diseases in Norway (i.e. PD and HSMI), autumn smolt have a higher risk of disease than spring smolts (Bang Jensen et al. 2012, Kristoffersen et al. 2013). Outbreaks of these diseases also occur mainly in the summer months, but unlike IPNV, which mostly infects smolts shortly after they have been transferred to the sea, the causative agents of these other diseases can infect fish throughout their lifecycle, and clinical disease can occur several months after initial infection (Kongtorp et al. 2006, Stene et al. 2014). Other factors, such as density and stocking period, were the same for both spring and autumn smolts, whereas the mean weight at sea transfer was a little higher for spring versus autumn smolts. However, this should not be a confounder, because according to the model, higher weight should be protective against IPN and mortality; thus, the negative effect of spring smolts is likely to be even larger than the model shows.

Several authors have shown regional differences in IPN outbreaks and mortality in Norway, but the mechanisms behind these differences have not been explained (Brun 2003). In the present study, we could not detect any geographical differences in either outbreaks or mortality. This is most likely due to the fact that the virus has now established itself throughout the country, after an initial phase with a higher concentration of outbreaks around the site of introduction in mid-Norway. We do, however, see a spatial effect, which is reflected in the variable infection pressure. The infection pressure will be dependent on different 
local factors, some of which are likely to be regionspecific, since the density of farms and distances between them varies among regions. For IPN, we found that number of fish or biomass in infected neighboring farms did not influence the infection pressure, which is thus the sum of 1 divided by the seaway distances to all IPN-infected cohorts within $100 \mathrm{~km}$ of the cohort. The significant effect of the infection pressure reflects the contagious nature of IPN in seawater and inclusion of this variable in the model is an elegant way of demonstrating the effect of having many infected neighbors. The results indicate that a strategy where the infection pressure is lowered, for example by removing infected cohorts, would have a beneficial effect on the control of IPN. However, such a strategy would have to be weighed with regard to the economic consequences of performing stamping-out.

A previous history of IPN on the same farm within the last $2 \mathrm{yr}$, corresponding to the previous cohort, increased the odds of getting IPN by a factor of 1.25. This is in agreement with the findings of Murray (2006), who used IPNV surveillance data to test for persistence in both marine and freshwater salmon farms. He found that while infection persisted for more than $4 \mathrm{yr}$ in freshwater farms, it was unlikely to persist for more than $2 \mathrm{yr}$ in marine farms, which, he argues, indicates that infection in marine farms is transient and therefore highly dynamic as compared to infection in freshwater farms.

A vital input for economic analysis is a valid estimation of the losses in the form of direct mortalities. Munro \& Midtlyng (2011) provided an overview of reported mortalities in Norwegian Atlantic salmon post-smolts. These range from $9.0 \%$ in 1993 to $17.8 \%$ in 1998. However, none of these studies covered the whole country and the collection of data was not standardized. In our univariate analysis, we found that cohorts that experienced clinical IPN had a mean cumulative mortality of $14 \%$, with an $80 \%$ range of 3.9 to $28.4 \%$. The corresponding numbers for cohorts without IPN were $6 \%$ and 1.2 to $12.8 \%$, respectively. When including all significant risk factors, the results from the model were that the mean mortality for IPN cohorts was $7.2 \%$ and $5.6 \%$ for spring and autumn cohorts, respectively. This was double the mortality for cohorts with no diseases (baseline cohorts). The mortality was 3.8 times higher than baseline if the cohort had IPN and PD, and almost 5 times higher if it had HSMI in addition. In all scenarios, the mortality varied by as much as $1.6 \%$ with different settings for temperature at sea. This illustrates that it is very important to include all significant factors when calculating mortality estimates.
As previously mentioned (see 'Results: Risk factors for IPN'), the risk of IPN decreased during the study period and the total mortality also decreased from $10.1 \%$ in 2009 to $6.2 \%$ in 2012 . The mortality for case cohorts only also decreased from $14.0 \%$ in 2009 to $10.1 \%$ in 2012 (data not shown), indicating that the direct economic effect in terms of losses decreased.

According to national fish health statistics collected by the NVI, there has been a dramatic decrease in the yearly number of IPN cases in post-smolts, from 144 in 2010 to 89 in 2012 and 39 in 2013 (Hjeltnes 2014). This reduction has been assigned mainly to the introduction of QTL-smolts with resistance for IPN and eradication of certain 'house strains' in hatcheries. In our study, we wanted to investigate whether the reduction could actually be ascribed to these 2 factors, by analyzing data collected from farmers. We did not find any statistically significant effect of QTL on either the risk of IPN or on the mortality. However, the dataset we had was very limited and contained very few cohorts that had used QTL fish. To address this question properly, the analysis need to be repeated with more data.

If the eradication of certain 'house strains' of IPNV in hatcheries has had an effect on IPN in marine farms, we should see a connection between IPN in the hatcheries and in the farms receiving fish from such hatcheries. We found that the probability of IPN in marine farms was not influenced by whether the farm had received smolts from hatcheries with clinical IPN or not. However, the influence on mortality in the marine farms was significant. The dataset used here did not have the same bias as the one for QTL-fish, but a problem was that we only had data on clinical outbreaks of IPN, and did not know whether some of the control farms might have been subclinically infected. Further, we did not know whether the actual fish that were transferred to the relevant farm had had IPN, only that there had been a clinical outbreak of IPN in the hatchery. Previous studies have been contradictory in terms of whether clinical outbreaks in the freshwater phase predispose fish to IPN in the marine phase (Brun 2003). There are 2 different hypotheses: (1) fry surviving an IPN outbreak will still harbor the virus and thus be at higher risk of another clinical outbreak after sea transfer, or (2) fry surviving a clinical outbreak will be immune to a subsequent outbreak. In order to investigate this further, we are currently carrying out a study on molecular tracing of IPN from hatchery to the marine phase.

Finally, Jarp et al. (1995) concluded that the risk of IPN increased when the farm had received smolts from more than 1 hatchery. Our analysis did not 
reveal any statistical significance between number of smolt suppliers and the occurrence of IPN, despite a dataset with a reasonable distribution of this variable. The negative effect of several smolt suppliers has been thought to be due to the mixing of fish with different susceptibilities to disease and different infection status, and a general social stress reaction to the mixing. In most farms in Norway today, the practice is to not mix smolts from different suppliers, but to transfer smolts from 1 tank at the hatchery to 1 corresponding cage in the farm. This is a possible explanation for why we do not see an effect now.

In summary, the most important option for the farmer wishing to avoid IPN outbreaks in his farms is to reduce the size of the cohort put to sea. To stock with autumn smolts only would have almost the same effect, but this might not be possible due to regulations on synchronized production. In addition, these smolts might have a higher risk for other diseases, so the benefit may disappear before the cohort reaches the time of harvest. Increasing the weight at sea transfer is another option that the farmer can actually influence, whereas the risk associated with stocking at low temperatures might be more difficult to mitigate. With regards to minimizing losses due to outbreaks of IPN, the most critical measure is to avoid co-infection with other diseases such as PD and HSMI.

Acknowledgements. This study was performed under the project 'Multifactorial diseases in Norwegian Atlantic salmon farming', funded by The Norwegian Seafood Research Fund. We wish to thank the industry partners of the project, who supplied us with data and inputs for the analyses.

\section{LITERATURE CITED}

Ariel E, Olesen NJ (2002) Finfish in aquaculture and their diseases - a retrospective view on the European Community. Bull Eur Assoc Fish Pathol 22:72-85

Bang Jensen B, Kristoffersen AB, Myr C, Brun E (2012) Cohort study of effect of vaccination on pancreas disease in Norwegian salmon aquaculture. Dis Aquat Org 102:23-31

Bang Jensen B, Brun E, Fineid B, Larssen RB, Kristoffersen AB (2013) Risk factors for cardiomyopathy syndrome (CMS) in Norwegian salmon farming. Dis Aquat Org 107:141-150

Bovo G, Håstein T, Hill B, LaPatra S and others (2005) FishEggTrade. Workpackage 1 report: Hazard identification for vertical transmission of fish disease agents. VESO, Oslo

Brun E (2003) Epidemiology. In: Skjelstad B, Brun E, Jensen I, Johansen LH and others (eds) IPN in salmonids a review. VESO and FHL, Trondheim, p 51-67

Hastie TJ, Tibshirani RJ (1996) Generalized additive models. Chapman \& Hall, London

Hjeltnes B (ed) (2014) Fish health report 2013. Norwegian Veterinary Institute, Oslo. Available at www.vetinst.
no/eng/Publications/Fish-Health-Report/Fish-HealthReport-2013

- Houston RD, Haley CS, Hamilton A, Guy DR and others (2008) Major quantitative trait loci affect resistance to infectious pancreatic necrosis in Atlantic salmon (Salmo salar). Genetics 178:1109-1115

Jarp J, Gjevre AG, Olsen AB, Bruheim T (1995) Risk factors for furunculosis, infectious pancreatic necrosis and mortality in post-smolt of Atlantic salmon Salmo salar L. J Fish Dis 18:67-78

Kilburn R, Murray AG, Hall M, Bruno DW, Cockerill D, Raynard RS (2012) Analysis of a company's production data to describe the epidemiology and persistence of pancreas disease in Atlantic salmon (Salmo salar L.) farms off Western Scotland. Aquaculture 368-369:89-94

Kongtorp RT, Halse M, Taksdal T, Falk K (2006) Longitudinal study of a natural outbreak of heart and skeletal muscle inflammation in Atlantic salmon, Salmo salar L. J Fish Dis 29:233-244

Kristoffersen AB, Viljugren H, Kongtorp RT, Brun E, Jansen PA (2009) Risk factors for pancreas disease (PD) outbreaks in farmed Atlantic salmon and rainbow trout in Norway during 2003-2007. Prev Vet Med 90:127-136

Kristoffersen AB, Bang Jensen B, Jansen PA (2013) Risk mapping of heart and skeletal muscle inflammation in salmon farming. Prev Vet Med 109:136-143

Moen T, Baranski M, Sonesson AK, Kjøglum S (2009) Confirmation and fine-mapping of a major QTL for resistance to infectious pancreatic necrosis in Atlantic salmon (Salmo salar): population-level associations between markers and trait. BMC Genomics 10:368

Munro ES, Midtlyng PJ (2011) Infectious pancreatic necrosis and associated aquatic birnaviruses. In: Woo PTK, Bruno DW (eds) Fish diseases and disorders, Vol 3: viral, bacterial and fungal infections, 2nd edn. CAB International, Oxfordshire, p 1-65

Murray AG (2006) A model for the emergence of infectious pancreatic necrosis virus in Scottish salmon farms 1996-2003. Ecol Model 199:64-72

NFD (Nerings- og fiskeri departementet) (2008) FOR 200806-17 nr 822: Forskrift om drift av akvakulturanlegg. Norwegian Ministry of Trade, Industry and Fisheries. Available at www.lovdata.no/cgi-wift/ldles?doc=/sf/sf/ sf-20080617-0822.html

OIE (Office International des Epizooties) (2006) Infectious pancreatic necrosis. In: Diagnostic manual for aquatic animal diseases, 5th edn. OIE, Paris, p 176-185

Raynard RS, Murray AG, Kilburn R, Leschen WA (2005) Infectious pancreatic necrosis (IPN) risk factors in seacultured Atlantic salmon (Salmo salar) in Scotland. In: Mellor DJ, Russell AM, Wood JLN (eds) Proc Soc Vet Epidemiology and Preventive Medicine Conf, Nairn, Scotland, 30 March-1 April 2005, p 113-123

R Core Team (2013) R: a language and environment for statistical computing. R Foundation for Statistical Computing, Vienna. www.R-project.org/

Smail DA, Bruno DW, Dear G, McFarlane LA, Ross K (1992) Infectious pancreatic necrosis (IPN) virus Sp serotype in farmed Atlantic salmon, Salmo salar L., post-smolts associated with mortality and clinical disease. J Fish Dis 15: 77-83

Stene A, Bang Jensen B, Knutsen Ø, Olsen A, Viljugrein H (2014) Seasonal increase in sea temperature triggers pancreas disease outbreaks in Norwegian salmon farms. J Fish Dis 37:739-751 